\title{
Quality-in(Process)Line (QulProLi) process intensification for a micro-flow UV-photo synthesis enabled by online UHPLC analysis
}

Citation for published version (APA):

Escriba Gelonch, M., Shahbazali, E., Honing, M., \& Hessel, V. (2018). Quality-in(Process)Line (QulProLi) process intensification for a micro-flow UV-photo synthesis enabled by online UHPLC analysis. Tetrahedron, 74(25), 3143-3151. https://doi.org/10.1016/j.tet.2018.02.016

DOI:

10.1016/j.tet.2018.02.016

Document status and date:

Published: 21/06/2018

Document Version:

Accepted manuscript including changes made at the peer-review stage

Please check the document version of this publication:

- A submitted manuscript is the version of the article upon submission and before peer-review. There can be important differences between the submitted version and the official published version of record. People interested in the research are advised to contact the author for the final version of the publication, or visit the $\mathrm{DOI}$ to the publisher's website.

- The final author version and the galley proof are versions of the publication after peer review.

- The final published version features the final layout of the paper including the volume, issue and page numbers.

Link to publication

\footnotetext{
General rights

- You may freely distribute the URL identifying the publication in the public portal. follow below link for the End User Agreement:

www.tue.nl/taverne

Take down policy

If you believe that this document breaches copyright please contact us at:

openaccess@tue.nl

providing details and we will investigate your claim.
}

Copyright and moral rights for the publications made accessible in the public portal are retained by the authors and/or other copyright owners and it is a condition of accessing publications that users recognise and abide by the legal requirements associated with these rights.

- Users may download and print one copy of any publication from the public portal for the purpose of private study or research.

- You may not further distribute the material or use it for any profit-making activity or commercial gain

If the publication is distributed under the terms of Article $25 \mathrm{fa}$ of the Dutch Copyright Act, indicated by the "Taverne" license above, please 
Quality-In(Process)Line (QuIProLi) process intensification for a micro-flow UVphoto synthesis enabled by online UHPLC analysis

Marc Escribà-Gelonch ${ }^{1^{*}}$, Elnaz Shahbazali ${ }^{1}$, Maarten Honing ${ }^{2}$, Volker Hesse ${ }^{1^{*}}$

${ }^{1}$ Eindhoven University of Technology, Department of Chemical Engineering and Chemistry, Group

Micro Flow Chemistry and Process Technology, De Rondom 70, 5612 AP Eindhoven, The Netherlands.

${ }^{2}$ Maastricht University, Imaging Mass Spectrometry, Minderbroedersberg 4-6, 6211 LK Maastricht,

The Netherlands.

\section{ABSTRACT}

Process intensification commonly enables reaction acceleration and therefore continuous-flow/PAT is urgently needed. The low volumes typical for micro-flow pose challenges for online sampling operations in analytics. In this paper, a very fast process is combined with a modified ultra-highperformance liquid chromatography (UHPLC) system allowing for very fast sampling and analysis. Lowvolume online sampling according to the needs posed by PAT for pharma quality control, is introduced here for UHPLC analysis of the photo-Claisen rearrangement in micro-flow. Chances and challenges are critically reviewed, including the reproducibility and robustness of the sampling. Furthermore, the ability and speed of the chosen set-up in order to capture process changes and adjust the process parameters properly is investigated. With the applied online sampling system, it was possible to perform, almost unattended and spending 12 times less sampling volume, a full factorial analysis of all relevant reaction conditions (243 experiments) in three days. Such quality-in-the-process-line (QuIProLi) online sampling avoided random errors due to automation.

Keywords: Process automation, flow chemistry, fast-sampling, UHPLC, Photo-Claisen rearrangement.

\section{INTRODUCTION}

Over the last 20 years, continuous micro-flow reactions have become an eminent topic in process design. ${ }^{1}$ The enhanced process control given through miniaturization results in many benefits such as higher yields, less waste, and improved sustainability. ${ }^{2}$ More far fetching, flow chemistry makes meanwhile possible the development of multi-step end-to-end platforms which deliver the product from raw materials (up to the pill in pharmaceutical manufacturing) in one continuous run. The need to keep control of such cascaded processing has paved the way for finding a suited analytical technology and fast detection which finally demand for process automation, ${ }^{3}$ reducing the human operator interaction to check a software interface. ${ }^{4,5,6,7,8}$ Nowadays the goal for multi-step processes is to be fully telescoped and managed by a single researcher. ${ }^{3}$ Therefore, continuous automated reaction monitoring can enhance the reliability and the quality of the final product, reducing labour and costs. ${ }^{9}$ In-time analytics are usually classified depending on where and how the sampling operation is carried out as: offline, atline, online and inline. ${ }^{10}$

Offline sampling in batch processing has some drawbacks even when its single steps are as fast as continuous micro-flow. First, the reaction outcome is often superimposed products by mass and heat transfer and even dependent on the location of sampling in the vessel, which is termed heterogeneity here. Therefore, in order to get the complete view, a large sample volume has to be taken at different points in the vessel. Complex statistical strategies are used in quality control of industrial chemical production. ${ }^{11}$ In addition, the heterogeneity of batch processes might cause higher errors or higher

\footnotetext{
${ }^{*}$ Corresponding authors:

Dr. Marc Escribà Gelonch (m.escriba.gelonch@tue.nl) and Prof. Volker Hessel (v.hessel@tue.nl).

${ }^{+}$Dr. Marc Escribà Gelonch and Elnaz Shahbazali share the first authorship.
} 
deviations between samples, and therefore lower confidence. These drawbacks are partially overcome sampling (offline) in continuous flow due to the (spatial and timely) homogeneity of sample qualities within the microcapillary. Thus a lower amount of sampling and samples is needed. Nevertheless, offline sampling still do not solve (i) the need for a minimum sampling volume to allow the, also longer, manual work-up, (ii) the possibility to damage or contaminate the sample during the operation, especially with air-/light-sensitive or short lifetime compounds, and subsequently (iii) the chance of errors. Here, inline/online analysis becomes a viable solution.

Intensified continuous flow provides order-of-magnitude shorter residence times ${ }^{12,13,14}$ and essentially needs ultrafast sampling operating with lower volumes and without interruption. As a consequence, the frequency of sampling and the time for analysis simply has to be faster than the time needed for completion of reaction and changing to the next process condition. Accordingly, online and inline analysis is preferred over atline and offline, and even those need to be speed up as given in this paper. An automation of online sampling also allows for the use of the precise volume needed, avoiding the unprecise manual sampling, which tends to increase the sampling volume in order to ensure enough quantity. In addition, automation also reduces random errors derived by manual operations, which take also more time to be carried out.

Recognizing the ambition of the United States Food and Drug (FDA) to establish continuous processing in pharmaceutical manufacturing by $2026^{15}$ and our previous flow chemistry research, ${ }^{16,17,18}$ the application of Process Analytical Technology (PAT) ${ }^{19,20}$ to flow chemistry is a major future goal relevant to the innovation of the paper. Here, real-time information accessibility has proven to enhance process control by reducing the timeline of the measurements, with the possibility to correct any leverage or malfunction in-time avoiding loses of chemicals. This creates a vast amount of data which typically demands for some extra data processing strategy. Established are multi-factorial mathematical analysis, statistical evaluations, model predictions, and algorithms like the Nelder-Mead simplex optimization algorithm. ${ }^{21}$ Common to all is to aim to optimize the pattern recognition of the variables or to improve even in two-dimensional fashion (e.g. temperature and reaction time). The traditional one-factor-at-a-time sometimes is not effective in explaining the interactions between factors. ${ }^{22,23}$

Coupling PAT systems to processes would avoid sample transfer and therefore their possible deterioration. In order to allow adequate monitoring and efficient reaction control, the sampling time and subsequent analysis has to be very short compared to the overall reaction time. In this connection, some analytical techniques are preferred, such as near infrared (NIR), ${ }^{24,25,26}$ Raman, ${ }^{27}$ Mid-IR, ${ }^{28}$ acoustic emission signals, ${ }^{29} \mathrm{X}$-ray absorption spectroscopy ${ }^{30}$ and nuclear magnetic resonance ${ }^{31,32}$ because of their analytical speed, non-contact spectroscopic analysis as well as their condition of not destructive methods. As an example, IR spectroscopy is commonly used for the determination of physical factors such as moisture, ${ }^{33}$ crystalline polymorphism, ${ }^{34}$ particle size, ${ }^{35}$ and density. ${ }^{36}$

Nonetheless, the development of PAT for monitoring of micro-flow chemistry has not largely reported. One reason might be the small volumes of chemicals in the micro-channels which pose a need for miniaturized versions of conventional analytical instruments. ${ }^{37}$ Therefore, process miniaturization requires an orders of magnitude smaller volume sampling, which in micro process engineering would mean easily most of the volume of the whole reactor. Some analytical techniques, which include sampling, fulfil that criterion such as Raman, ${ }^{38}$ liquid chromatography, ${ }^{39}$ or capillary electrophoresis. ${ }^{40,41}$ However, for small molecule analysis, high-performance liquid chromatography (HPLC) is commonly preferred and is quasi the unique method used for process monitoring applications in micro-channels offline. HPLC coupled to microreactors have been applied for the synthesis of, e.g., cycloadducts, ${ }^{42}$ pyrazoles ${ }^{43}$ and ciprofloxacin analogues. ${ }^{44}$ Flow automation has also reached continuous multistep systems. ${ }^{45}$ The work of Kock et al. ${ }^{46}$ shows one issue to be solved around 
automated flow operation. 51 samples $(0.2 \mathrm{mg}$ solution) collection needed as much as $5.6 \mathrm{~h}$ sampling time. Also, the length of the chromatographic methods still is a main problem for the use HPLC for online micro-flow process monitoring. ${ }^{47}$ Other issues are the analysis costs, ${ }^{37}$ as well as the long equilibration times when non-isocratic conditions are used..$^{40}$

Yet, with the already proven ultra-high-performance liquid chromatography (UHPLC) conditions, analysis times are shortened significantly. Together with micro column approaches, low sample volumes are feasible, allowing fast sequential experiments, and also novel process time windows to keep the quality-in-the-process-line (QulProLi). As an example, UHPLC allows to operate free of constraints by heat transfer limitations, much different from batch experiments. ${ }^{48}$ Indeed since recently there is evidence for advanced process control with the goal of fast kinetic screening, ${ }^{49,50,51,52,53}$ biological analysis ${ }^{54,55,56}$ and mechanistic studies ${ }^{57,58}$ under stable, well reproducible reaction conditions. The combination of flow chemistry and online monitoring gives also the chance for nonstop UHPLC continuous analytics, when spectroscopic online analytic sources, e.g. FTIR or NMR, are not suitable because of (i) specific products which overlap signals, (ii) reactions performed in very low concentrations, or (iii) simply because in a microchannel the amount of analyte is not enough for an accurate measurement. As an example, online UHPLC coupled with a Teflon/FEP-capillary-based flow microreactor has been reported as especially effective for the analysis of non-volatile organic molecules because of the rapid separation achieved. ${ }^{59}$ However and as outlined above, the sampling step of UHPLC remains an issue, because of the small volumes supplied by the small channels. Attiya et $a I^{.60}$ and Lin et al. ${ }^{61}$ reported in 2001 the first approaches to online sampling using micro-channels, but both applied to electrophoresis. Schlund et al. ${ }^{62}$ reported in 2007 the first continuous sampling applied to HPLC based on a double-T junction emulating an HPLC injector loop. Also, fraction collectors have been used for sampling operation in microchannels. ${ }^{63}$ Therefore, the next step in micro-flow based reaction development should be to determine the optimal operating speed, as suggested by FDA. ${ }^{64}$

In this paper, the combination of flow chemistry with a modified UHPLC system allowing rather fast online sampling is discussed. As a proof-of-concept, this configuration was tested in combination with a photo-Claisen rearrangement reaction. We previously reported the thermal Claisen rearrangement of allyl phenyl ether (APE) to ortho-allyl phenol (Figure 1) achieving process intensification ${ }^{65}$ without the need of a catalyst. Latter an intensification of micro flow route for photo-Claisen rearrangement was also reported. ${ }^{66}$ The photo pathway gave para-substituted isomer besides of ortho-substituted given by thermal process. The latter opened the chance of a new radicalary unexplored path. Therefore, the photo-reaction path used in this study and given in Figure 1, offers still an attractive way for research in an automated fashion. Here, after carrying out the reaction in the capillary photoreactor, samples are automatically taken and subsequently analysed using short timing enabled by the modified UHPLC system coupled to the setup. The different residence times for the different operations, the number of samples, the process simplification and the process automation are parameters taken into account.

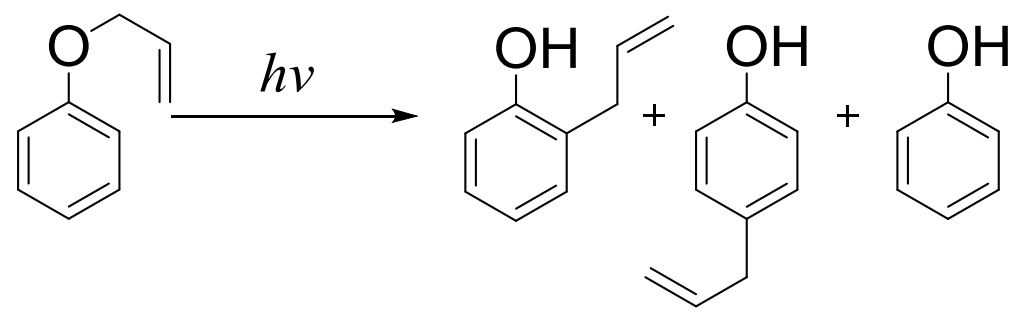

Figure 1: Photo-Claisen rearrangement path used in online sampling. 


\section{EXPERIMENTAL PART}

\subsection{Experimental setup}

Microchannel experiments have been performed using the reactor set-up depicted in Scheme 1. The setup is composed of two HPLC pumps (Knauer Azura P4.1S). The first feeds a $0.5 \mathrm{M}$ stock solution of APE (Sigma Aldrich 99\%, $16.77 \mathrm{~g}, 125 \mathrm{mmol}$ ) in $250 \mathrm{~mL} \mathrm{n}$-butanol (Sigma Aldrich). The second feeds pure $\mathrm{n}$-butanol and is used to arrange, in-flow and in one run, the experiments carried out using $0.1 \mathrm{M}$ and $0.05 \mathrm{M}$ concentration. A T-mixer (Valco) is subsequently used for this purpose. The flow-rate is adjusted accordingly to achieve reaction times of 2, 5 and 8 minutes respectively. Inside an oven, a low-pressure amalgam UV-lamp with distinctive peak at $254 \mathrm{~nm}$ (TS23-212; Dinies Technologies $\mathrm{GmbH}$ ) is installed, and $5 \mathrm{~m}$ (approx. $1 \mathrm{~mL}$ equivalent volume) UV-transparent fluorinated ethylene propylene capillary tubing (FEP 1548, $0.5 \mathrm{~mm}$ ID; Upchurch Scientific) is wound on a metallic tower around the cylindrical shaped lamp. Accordingly, the tubing is properly connected to the T-mixer in the inlet and to the sampling unit in the outlet of the oven. Just before online UHPLC connection, a T-piece (IDEX) allows for offline sampling.

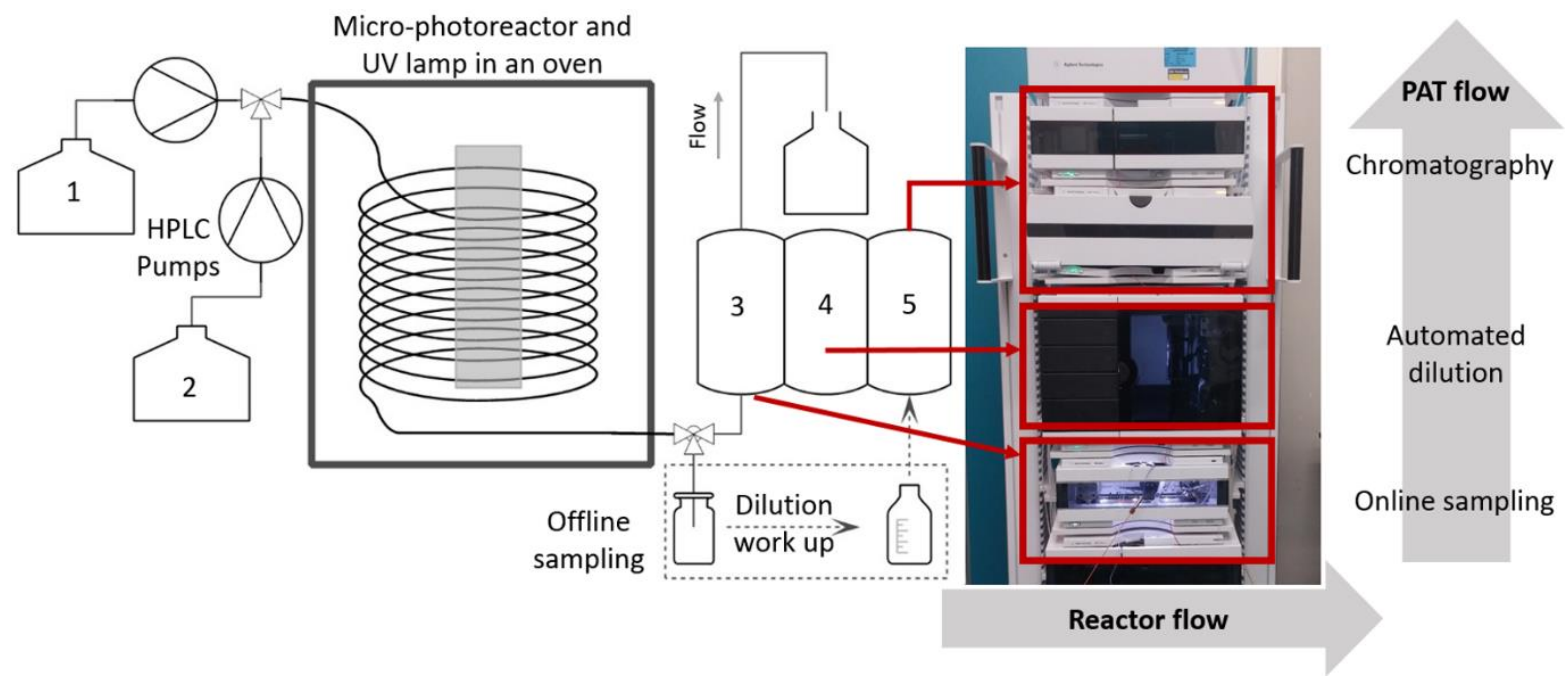

Scheme 1: Photo-Claisen rearrangement setup coupled to offline and online sampling. 1: Stock solution of alkyl phenyl ether in n-butanol. 2: n-butanol. 3: online autosampling. 4: Automated dilution. 5: UHPLC analyzer.

\subsection{Experimental conditions of sampling and chromatographic separation.}

Allyl phenyl ether, 1-butanol, formic acid, acetonitrile, and 1,3-dinitrobenzene were purchased from Aldrich chemical company and used as received. The solvents purity were all according to HPLC grade of Sigma-Aldrich solvents (>99.5). The online UHPLC system was based on an Agilent 1290 Infinity II LC system (Scheme 1) consisting of a binary pump, an autosampler, a thermostated column compartment and a diode array detector equipped with a $10 \mathrm{~mm}$ Max-Light Cartridge Cell. Analytical isocratic separation was achieved with an Agilent ZORBAX Eclipse Plus C18 UHPLC column $(2.1 \times 50 \mathrm{~mm}, 1.8 \mu \mathrm{m})$ and applying a mixture of $0.1 \%$ formic acid in water and acetonitrile $(55 / 45 ; \mathrm{v} / \mathrm{v})$ as the mobile phase. The detection was carried out with a UV-visible diode array detector at $270 \mathrm{~nm}$, and data processing performed with the Agilent OpenLAB ChemStation software. The analytical setup was linked to the flow reactor by means of an "in-house" modified autosampler (an item of a patent application), encompassing a series of multi-port valves, which allows the direct sampling from the outlet of the 
flow reactor. The sampling cycle was programmed to perform a system purge, sampling and dilution followed by separation and detection. $40 \mu \mathrm{L}$ sample was trapped before being diluted with acetonitrile to a total volume of $100 \mu \mathrm{L}$. An aliquote of $1 \mu \mathrm{L}$ was subsequently injected onto the analytical column.

\section{RESULTS AND DISCUSSION}

\subsection{Online sampling and analytic time distribution}

The first goal was to investigate three experimental parameters with certain discrete values for the photo-Claisen reaction as fast as possible using the online UHPLC-UV analyser, i.e. to show minimal analysis time demands and to benchmark this to any combination of conventional and micro-flow processing with conventional analytics. These three parameters were considered: temperature $(T)$, concentration (c) and reaction time (t). Concerning temperature, the values were $21^{\circ} \mathrm{C}, 35^{\circ} \mathrm{C}$ and 50 ${ }^{\circ} \mathrm{C}$, for concentration $0.05 \mathrm{M}, 0.1 \mathrm{M}$ and $0.5 \mathrm{M}$, and for reaction times were $2 \mathrm{~min}, 5 \mathrm{~min}$ and $8 \mathrm{~min}$. Each operation was timed using a chronometer.

\subsubsection{Timing of sampling, analysis, and settling time for next experiment}

Figure 2 gives the time distribution for testing three flow rates at one temperature and one concentration, here referred as one cycle. In this Figure, the fragment striped refers to the settling and stabilization time (here, three residence times were taken). Also the dead time refers to the delay of setting the conditions in flow. Despite of the advantages of flow chemistry in terms of heat and mass transfer, the existence of such dead time frames suggest that flow chemistry could not be fast enough in this case. After setting them three online samples were taken, all of them with the same protocol. In total, the sampling operation (including sampling and automatic work-up) lasted 7 min. After sampling, a new flow rate was set. During the stabilization time, the UHPLC analysed automatically all samples and the results were taken before the new sampling (Figure 3). In addition, during the next sampling operation, the results of the previous samples were processed by the user (Figure 3). As a consequence, 9 samples in 3 different conditions were taken, analysed in parallel and the results were processed. The online test speed then was set at $72 \mathrm{~min} / \mathrm{cycle}$. It is relevant to note that the time for sampling and analysis was usually shorter than the time for setting new conditions. Then this ultrafast procedure becomes faster than continuous flow intensification. In addition, the researcher only needed to set the conditions and get the results, which reduced drastically the random error derived of manual operation. Thus, three flow rates were triple tested largely automated in somewhat more than one hour ten minutes. In this way, for each of the 3 flow rates, 3 temperatures and 3 concentrations ( 9 cycles) were tested in just a bit more than 10 hours in the same day. Thus, the parametric variations sum up to $3 \times 3 \times 3=27$ measurements. As all of them were repeated three times, 81 samples were achieved in one run and one day. The same set of experiments was carried out in 3 different days, during which 27 conditions were three times tested and 243 samples were taken, analysed and the results were processed. 


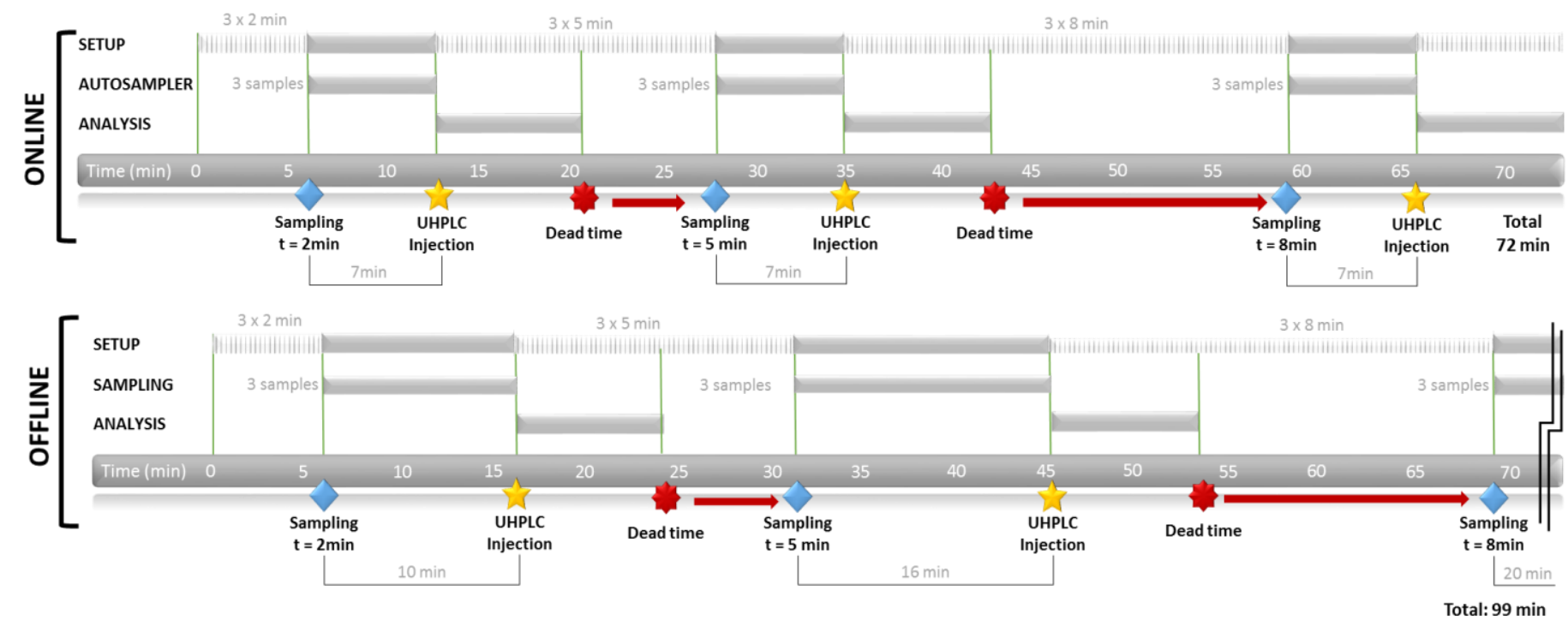

Figure 2: Timeline for sequentially testing 3 flow rates at the same temperature and concentration. Online sampling allowed for, 9 samples (taken and analyzed) in $72 \mathrm{~min}$. Offline sampling needed around $30 \mathrm{~min}$ more. The fragment striped refers to the time needed to set and stabilize the new conditions ( 3 residence times).

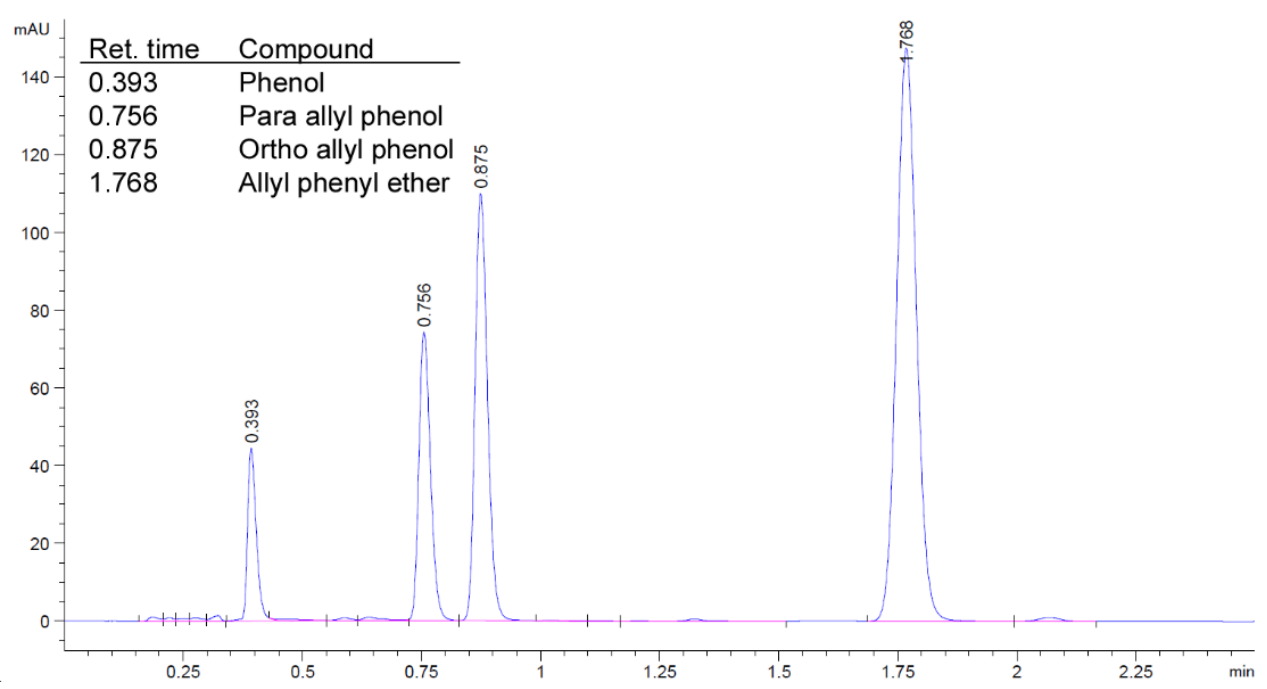

Figure 3: Online sample chromatogram of $0.05 \mathrm{M} \mathrm{APE}$, using 2 min reaction time at $21^{\circ} \mathrm{C}$.

\subsubsection{Sampling volume}

The same set of experiments was carried out offline. Here both sampling and dilutions were performed manually. The sampling time was set according to the reactor flow-rate in order to achieve $0.5 \mathrm{ml}$ sample. An important point to highlight is the fact that this sampling volume means almost the half of the volume of the whole capillary microreactor. In addition, online sampling needed 12 times less volume to perform the same experiments, as shown in Figure 4, which is more suitable for low volumes used in flow chemistry. Batch sampling in Figure 4 refers to 5 sampling points in a batch reactor $(4 \mathrm{~h}$ irradiation time according to Pitchumani et al. ${ }^{67}$ ). In continuous flow, for 2, 5 and 8 min residence time, $1 \mathrm{~min} / \mathrm{sample} 3 \mathrm{~min} / \mathrm{sample}$ and $4.25 \mathrm{~min} / \mathrm{sample}$ were needed respectively. Therefore, in Figure 5 it is noted that the difference between online and offline sampling increases when the flow rate in the reactor decreases, because of the time needed offline to get $0.5 \mathrm{~mL}$ of sample even with low flow 
rates. The subsequent work-up of three samples in order to get the final injection vials was set in 6 min. This operation is reduced drastically online in terms of time, avoiding also random errors. Overall, offline sampling operation and work-up needed $10 \mathrm{~min}, 16 \mathrm{~min}$ and $20 \mathrm{~min}$ for 2, 5 and $8 \mathrm{~min}$ reaction time respectively for each sample. Figure 2 shows the compared timeline online/offline for each cycle of experiments. The difference in time was set to almost half an hour for each cycle, which means online sampling delivered 4.5 hours less, therefore in overall, online experiments saved $40 \%$ time.

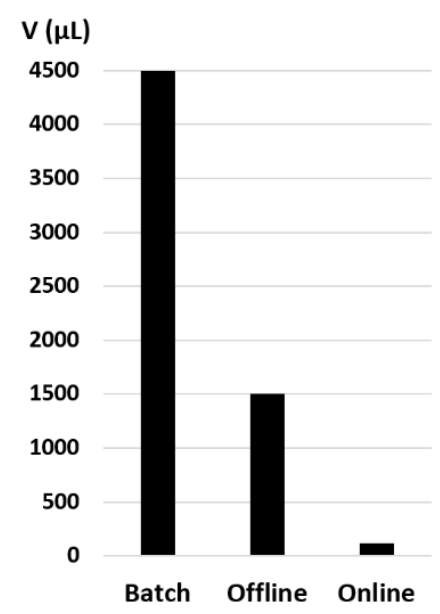

Figure 4: Comparison between the needed volumes for every set of 3 samples.

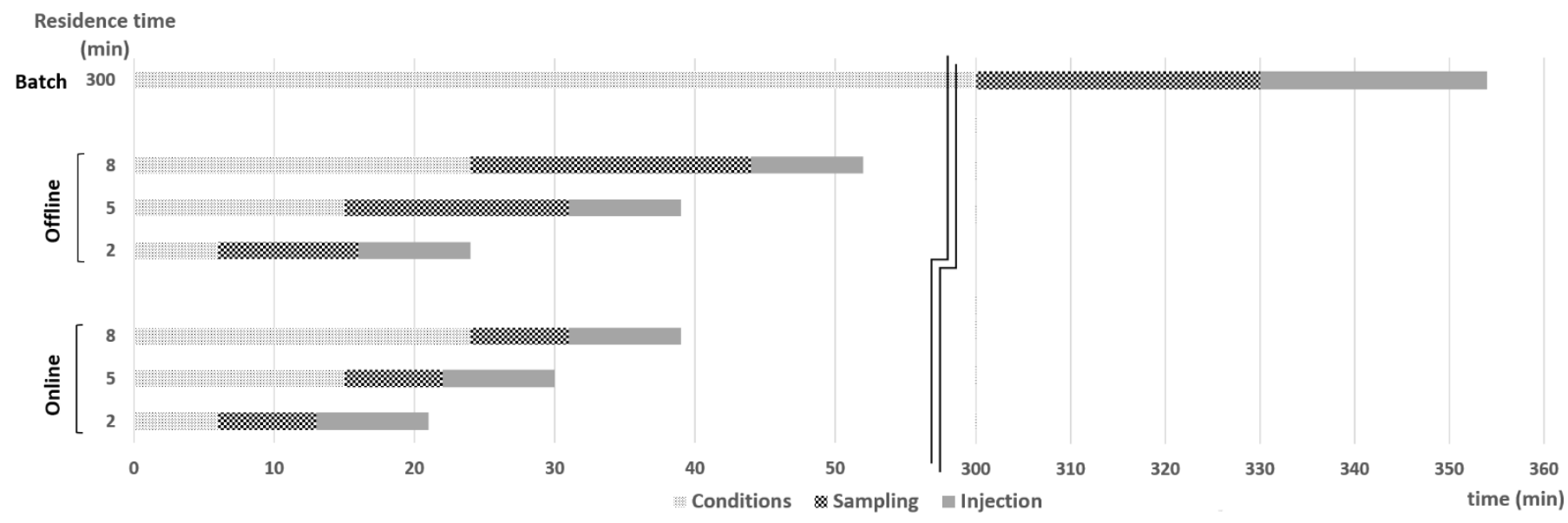

Figure 5: Comparison between sampling procedures for a single set of 3 samples at low, medium and high residence times, equivalent to high, medium and low flow rates respectively.

\subsubsection{Sampling reliability and robustness}

Table 1 shows the average values, their standard deviation and their variation coefficient (VC) of each set of experiments performed in the 3 days. The repeatability is characterized by the VC and found in all cases to be below $3 \%$ using low and medium concentrations. Nevertheless, when increasing the concentration, the variability was found to be higher, especially in low residence times. This finding could be explained by (i) the viscosity of the final solution at high concentration (viscosity of just $n$ butanol is rather high: $2.6 \mathrm{mPa} \cdot \mathrm{s}$ at $25^{\circ} \mathrm{C}$ ), ${ }^{68}$ which can modify the rheology and the hydrodynamics making difficult to achieve a homogeneous sampling at the same drawing speed. Furthermore, (ii) the precision could be compromised because of solubility constraints due to the incomplete reaction of precipitated ortho allylphenol. In fact, it was observed that at high concentrations the solution sometimes became not fully homogeneous because of the close solubility limit. This could be a limitation for representative sampling, since an online particulate matter of $40 \mu \mathrm{L}$ might be not 
sufficient compared to $0.5 \mathrm{~mL}$ in offline sampling. The viscosity- and solubility-related explanation is in line with the finding that the repeatability is improved with an increase of temperature.

\begin{tabular}{|c|c|c|c|c|c|c|c|c|c|c|c|c|c|c|}
\hline \multicolumn{3}{|c|}{ Concentration $(\mathrm{M}) \rightarrow$} & \multicolumn{4}{|c|}{0,05} & \multicolumn{4}{|c|}{0,1} & \multicolumn{4}{|c|}{0,5} \\
\hline Day & $\mathrm{T}\left({ }^{\circ} \mathrm{C}\right)$ & $t(\min )$ & $\begin{array}{c}\text { Conversion } \\
(\%)\end{array}$ & & d. Dev. & $\%$ VC & $\begin{array}{c}\text { Conversion } \\
(\%)\end{array}$ & & d. Dev. & $\% \mathrm{VC}$ & $\begin{array}{c}\text { Conversion } \\
(\%)\end{array}$ & & I. Dev. & $\%$ VC \\
\hline \multirow{9}{*}{1} & \multirow{3}{*}{21} & 2 & 49.7 & \pm & 0.772 & 2 & 30.4 & \pm & 0.916 & 3 & 6.0 & \pm & 1.565 & 26 \\
\hline & & 5 & 82.5 & \pm & 0.228 & 0 & 55.5 & \pm & 0.563 & 1 & 15.7 & \pm & 1.267 & 8 \\
\hline & & 8 & 94.5 & \pm & 0.047 & 0 & 72.4 & \pm & 0.321 & 0 & 23.1 & \pm & 0.227 & 1 \\
\hline & \multirow{3}{*}{35} & 2 & 51.0 & \pm & 0.409 & 1 & 31.9 & \pm & 0.102 & 0 & 8.8 & \pm & 1.561 & 18 \\
\hline & & 5 & 83.4 & \pm & 0.167 & 0 & 57.0 & \pm & 0.025 & 0 & 20.0 & \pm & 1.361 & 7 \\
\hline & & 8 & 94.6 & \pm & 0.027 & 0 & 74.4 & \pm & 0.096 & 0 & 27.6 & \pm & 1.118 & 4 \\
\hline & \multirow{3}{*}{50} & 2 & 59.9 & \pm & 0.611 & 1 & 39.0 & \pm & 0.025 & 0 & 9.5 & \pm & 0.428 & 4 \\
\hline & & 5 & 89.2 & \pm & 0.422 & 0 & 71.0 & \pm & 0.015 & 0 & 22.0 & \pm & 0.071 & 0 \\
\hline & & 8 & 94.0 & \pm & 0.203 & 0 & 85.9 & \pm & 0.015 & 0 & 32.0 & \pm & 0.041 & 0 \\
\hline \multirow{9}{*}{ II } & \multirow{3}{*}{21} & 2 & 42.5 & \pm & 0.303 & 1 & 31.0 & \pm & 0.040 & 0 & 7.3 & \pm & 1.042 & 14 \\
\hline & & 5 & 72.5 & \pm & 0.710 & 1 & 50.5 & \pm & 0.305 & 1 & 13.8 & \pm & 0.335 & 2 \\
\hline & & 8 & 87.6 & \pm & 0.190 & 0 & 69.0 & \pm & 0.238 & 0 & 19.3 & \pm & 0.697 & 4 \\
\hline & \multirow{3}{*}{35} & 2 & 43.0 & \pm & 0.463 & 1 & 30.0 & \pm & 0.070 & 0 & 5.1 & \pm & 1.811 & 36 \\
\hline & & 5 & 72.6 & \pm & 0.369 & 1 & 55.0 & \pm & 0.026 & 0 & 13.8 & \pm & 1.250 & 9 \\
\hline & & 8 & 87.8 & \pm & 0.270 & 0 & 70.6 & \pm & 0.544 & 1 & 23.0 & \pm & 0.673 & 3 \\
\hline & \multirow{3}{*}{50} & 2 & 65.0 & \pm & 0.027 & 0 & 38.6 & \pm & 0.717 & 2 & 10.0 & \pm & 0.463 & 5 \\
\hline & & 5 & 91.0 & \pm & 0.044 & 0 & 68.1 & \pm & 0.040 & 0 & 19.9 & \pm & 0.250 & 1 \\
\hline & & 8 & 95.5 & \pm & 0.016 & 0 & 83.0 & \pm & 0.053 & 0 & 30.0 & \pm & 0.034 & 0 \\
\hline \multirow{9}{*}{ III } & \multirow{3}{*}{21} & 2 & 46.1 & \pm & 1.454 & 3 & 33.2 & \pm & 0.614 & 2 & 6.3 & \pm & 1.399 & 22 \\
\hline & & 5 & 77.9 & \pm & 0.377 & 0 & 56.0 & \pm & 0.093 & 0 & 17.1 & \pm & 0.962 & 6 \\
\hline & & 8 & 91.5 & \pm & 0.038 & 0 & 74.0 & \pm & 0.091 & 0 & 23.6 & \pm & 1.171 & 5 \\
\hline & \multirow{3}{*}{35} & 2 & 45.0 & \pm & 0.417 & 1 & 29.8 & \pm & 0.817 & 3 & 7.2 & \pm & 1.797 & 25 \\
\hline & & 5 & 76.8 & \pm & 0.037 & 0 & 56.5 & \pm & 0.684 & 1 & 18.7 & \pm & 0.933 & 5 \\
\hline & & 8 & 90.9 & \pm & 0.162 & 0 & 73.1 & \pm & 0.091 & 0 & 23.9 & \pm & 0.054 & 0 \\
\hline & \multirow{3}{*}{50} & 2 & 58.0 & \pm & 0.118 & 0 & 38.1 & \pm & 0.220 & 1 & 11.0 & \pm & 0.303 & 3 \\
\hline & & 5 & 86.7 & \pm & 0.187 & 0 & 68.0 & \pm & 0.218 & 0 & 22.0 & \pm & 0.105 & 0 \\
\hline & & 8 & 97.5 & \pm & 0.103 & 0 & 85.5 & \pm & 0.235 & 0 & 33.5 & \pm & 0.036 & 0 \\
\hline
\end{tabular}

Table 1: Average values of three repeated online measurements of photo-Claisen reaction conversions obtained at three different days. (VC = variation coefficient)

Table 2 summarizes the reproducibility of these results. The term reproducibility is used, as the same experiment carried out under the same conditions but at different days. Then, Table 2 gives the deviation between the mean values of the same three reproducible experiments carried out in different days. The majority of the VC values are below $10 \%$, except the ones at higher concentration. Rheological and solubility issues may explain these results as described above. 


\begin{tabular}{|c|c|c|c|c|c|c|c|c|c|c|c|c|c|}
\hline \multicolumn{2}{|c|}{ Concentration $(\mathrm{M}) \rightarrow$} & \multicolumn{4}{|c|}{0.05} & \multicolumn{4}{|c|}{0.1} & \multicolumn{4}{|c|}{0.5} \\
\hline $\mathrm{T}\left({ }^{\circ} \mathrm{C}\right)$ & $\mathrm{t}(\min )$ & $\begin{array}{c}\text { Conversion } \\
(\%)\end{array}$ & & Dev. & $\% \mathrm{VC}$ & $\begin{array}{c}\text { Conversion } \\
(\%)\end{array}$ & & td. Dev. & $\% \mathrm{VC}$ & $\begin{array}{c}\text { Conversion } \\
(\%)\end{array}$ & & d. Dev. & $\% \mathrm{VC}$ \\
\hline \multirow{3}{*}{21} & 2 & 46.1 & \pm & 3.602 & 8 & 31.5 & \pm & 1.477 & 5 & 6.6 & \pm & 0.690 & 10 \\
\hline & 5 & 77.6 & \pm & 5.006 & 6 & 54.0 & \pm & 3.070 & 6 & 15.6 & \pm & 1.633 & 10 \\
\hline & 8 & 91.2 & \pm & 3.480 & 4 & 71.8 & \pm & 2.577 & 4 & 22.0 & \pm & 2.388 & 11 \\
\hline \multirow{3}{*}{35} & 2 & 46.4 & \pm & 4.166 & 9 & 30.6 & \pm & 1.178 & 4 & 7.0 & \pm & 1.868 & 26 \\
\hline & 5 & 77.6 & \pm & 5.479 & 7 & 56.1 & \pm & 1.032 & 2 & 17.5 & \pm & 3.258 & 19 \\
\hline & 8 & 91.1 & \pm & 3.376 & 4 & 72.7 & \pm & 1.880 & 3 & 24.8 & \pm & 2.441 & 10 \\
\hline \multirow{3}{*}{50} & 2 & 60.9 & \pm & 3.618 & 6 & 38.6 & \pm & 0.454 & 1 & 10.2 & \pm & 0.752 & 7 \\
\hline & 5 & 89.0 & \pm & 2.136 & 2 & 69.0 & \pm & 1.718 & 2 & 21.3 & \pm & 1.209 & 6 \\
\hline & 8 & 95.6 & \pm & 1.741 & 2 & 84.8 & \pm & 1.568 & 2 & 31.8 & \pm & 1.743 & 5 \\
\hline
\end{tabular}

Table 2: Averages of three repeated online measurements of photo-Claisen reaction conversions obtained at different days.

\subsection{Analysis of the confidence in the results obtained}

As described above, simultaneously to the online sampling, conventional samples in $5 \mathrm{~mL}$ vials (VWR International) were taken in parallel for each set of conditions. These samples were manually diluted and injected in the same UHPLC using the conventional procedure of injection from vials. These results were used to compare offline sampling and sample preparation with online sampling. Hence, each online average and deviation value was opposed to the corresponding offline average and deviation value. The subtraction of these paired results generated a new variable defined as $W=$ online - offline. Statistical procedures were used to study this new variable using Statgraphics Centurion VII. In ideal conditions, the average of this variable should be 0 with 0 deviation, which means that the result obtained by online would be exactly the same, as the corresponding offline sample. Figure 6 shows the frequency histogram of $W$, where a Gauss bell shows a slight tendency of a leverage in the 0 value of $\mathrm{W}$. Figure 7 shows the normal test which suggests that the values of $\mathrm{W}$ can be represented by a normal distribution at $95 \%$ of confidence level. The latter is relevant in order to carry out further hypothesis tests and set the interval of confidence of $\mathrm{W}$.

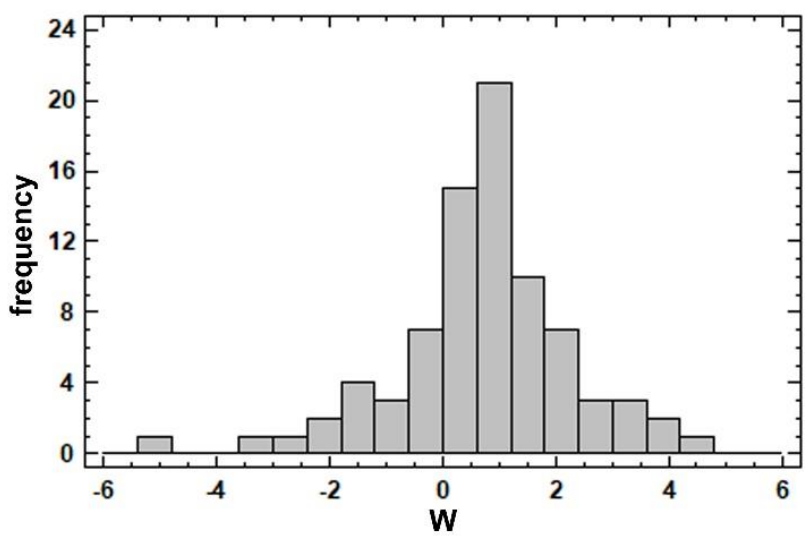

Figure 6: Frequency histogram of variable $\mathrm{W}$ 


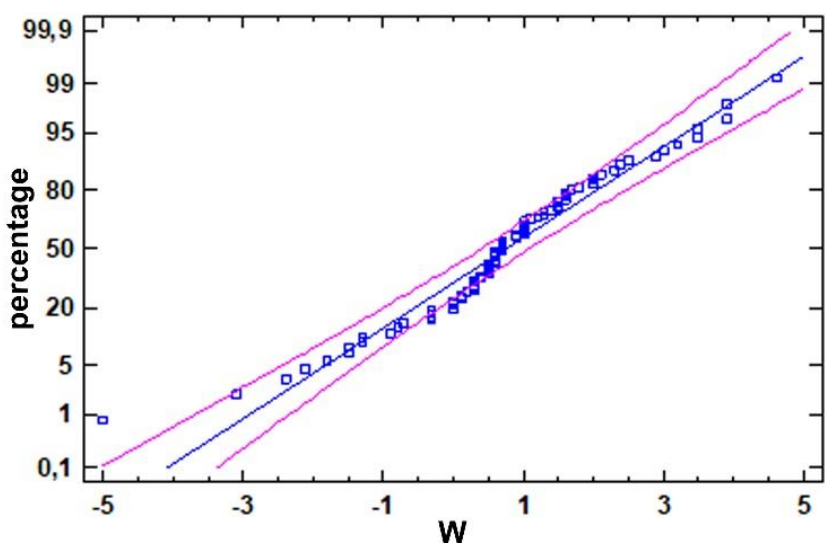

Figure 7: Normality test for W.

In a context of normality, a hypothesis test was performed in order to determine if it could statistically be accepted that the average of $\mathrm{W}$ is zero, and therefore the results online are as reliable as offline. The null hypothesis of the T-test was subsequently: average equal to 0 , giving an alternative hypothesis of non-equality. Unfortunately, this test was rejected with $95 \%$ confidence level, concluding that the average of $\mathrm{W}$ is not 0 , and therefore a systematic leverage has to be accepted. In order to delimit this leverage, a new test was performed based on the distribution of $W$ showed in Figure 6 . The assumption that the average value equals 0.5 was checked. As a result, the P-value of this test was 0.0677836 which is above the significance level of 0.05 . Hence, in these conditions the null hypothesis cannot be rejected at the $95 \%$ confidence level. Therefore, it can be accepted that the average value of $W$ is +0.5 , which means that the systematic difference for the online sampling compared to manual sampling and dilution is $+0.5 \%$.

In order to set the interval of confidence of $W$, a new hypothesis test was performed to fix the standard deviation. In this case a Chi-squared test ${ }^{69}$ was performed. Considering Figure 6 , the null hypothesis was set to be equal to 1.4 versus the alternative hypothesis of different. This test gave a P-value of 0.138879 , above the significance level of 0.05 . Hence the value of 1.4 can be accepted as the standard deviation of $W$ at the $95 \%$ confidence level. Therefore, it can be concluded the variable $W$ is normally distributed and has an average of 0.5 with a standard deviation of 1.4. Transferring this conclusion to the sampling, the online sampling gives $0.5 \%$ higher conversion $\pm 1.4 \%$ compared to offline sampling.

\subsection{Statistical approach of the Photo-Claisen reaction parameters}

Taking advantage of the experiments carried out, an additional study of the effect of the reaction conditions in the conversion of the photo-Claisen reaction was performed, using one of the sets of online experiments which corresponds to almost one day working. In this connection, a balanced completely randomized design was performed using the 3 levels of each factor ( $T, c$ and $t)$ as described above. All data were analysed using generalized linear model (PROC GLM) of SAS (V9.0, SAS Institute Inc., Cary, NC, USA). ${ }^{70}$ The significance of the analysis of variance was set at 0.05 and a Duncan's multiple comparison test was added. ${ }^{71}$ Table 3 (up) shows the significance of the model and Table 3 (down) shows the analysis of variance (ANOVA) derived from the statistical analysis. Here, the Fstatistic refers to a ratio of two variances: variation between sample means and variation within the samples. Thus, higher dispersion gives higher $\mathrm{F}$ value, which means that concentration gives more variability on the APE conversion than reaction time and temperature. 


\begin{tabular}{|r|rrrrr|}
\hline Source & DF & Sum of Squares & Mean Square & F Value & Pr $>$ F \\
\hline Model & 26 & 66792.62840 & 2568.94725 & 360.28 & $<.0001$ \\
Error & 54 & 385.04667 & 7.13049 & & \\
Corrected Total & 80 & 67177.67506 & & &
\end{tabular}

\begin{tabular}{|l|lllll|}
\hline Source & DF & Type I /III SS & Mean Square & F Value & Pr $>$ F \\
\hline $\mathrm{T}$ & 2 & 1477.26247 & 738.63123 & 103.59 & $<.0001$ \\
$\mathrm{C}$ & 2 & 46782.28469 & 23391.14235 & 3280.44 & $<.0001$ \\
$\mathrm{~T} * \mathrm{C}$ & 4 & 120.27457 & 30.06864 & 4.22 & 0.0048 \\
$\mathrm{t}$ & 2 & 16290.81654 & 8145.40827 & 1142.33 & $<.0001$ \\
$\mathrm{~T} * \mathrm{t}$ & 4 & 14.45383 & 3.61346 & 0.51 & 0.7309 \\
$\mathrm{C} * \mathrm{t}$ & 4 & 1928.20049 & 482.05012 & 67.60 & $<.0001$ \\
$\mathrm{~T} * \mathrm{C} * \mathrm{t}$ & 8 & 179.33580 & 22.41698 & 3.14 & 0.0054 \\
\hline
\end{tabular}

Table 3: Significance of the GLM model (up) and the ANOVA derived of this analysis (down).

Table 3 shows that all single variables: $T, c$ and t have significant $(P<0.001)$ differences in their levels. Therefore, the APE conversion of the photo-Claisen reaction is different at different concentrations, different temperatures and different residence times. Nevertheless, apparently the interaction $T^{*} t$ is not significant, which means that the variability of the conversion when using different residence times is statistically the same when using different temperatures. Hence, parallel lines are expected in the $T^{*}$ t interaction plot (Figure 8). In this plot, the $21^{\circ} \mathrm{C}$ and $35^{\circ} \mathrm{C}$ lines are close to each other, which can be correlated with a statistically identic behaviour related to the conversion. The latter is confirmed by the Duncan's test (Table 4), which means that the same conversion profile is obtained by operating at $21^{\circ} \mathrm{C}$ and at $35^{\circ} \mathrm{C}$. In the light of these results, it can be concluded that maximal APE conversion of the photoClaisen reaction is achieved at high temperature $\left(50^{\circ} \mathrm{C}\right)$, low concentration $(0.05 \mathrm{M})$ and long residence time (8 $\mathrm{min}$ ). This is also shown on the 3D plot in Figure 9.

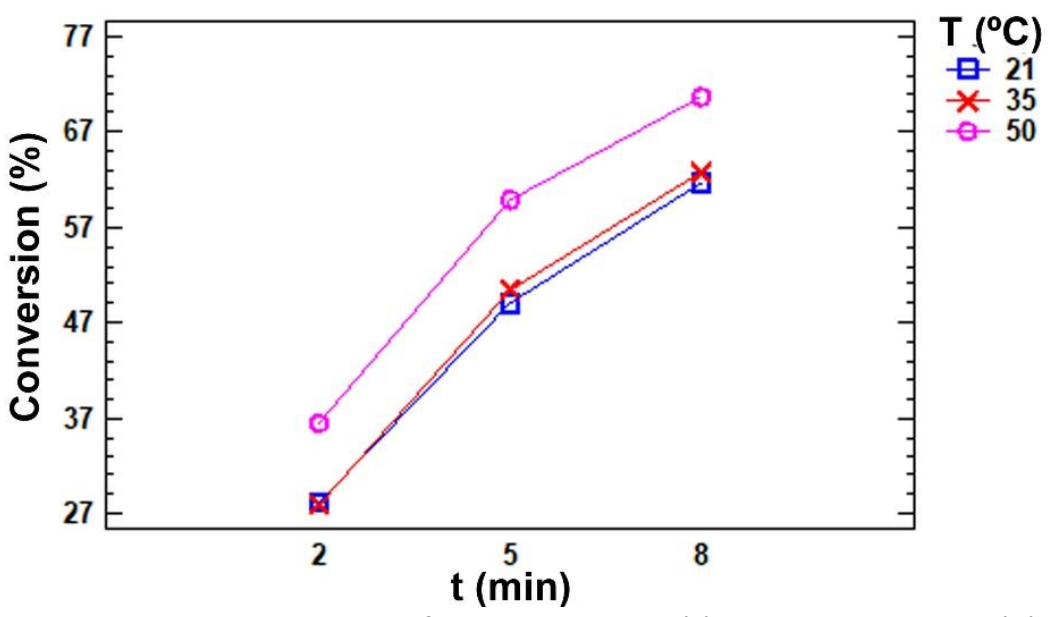

Figure 8: Interaction plot of residence time (t) and temperature $(\mathrm{T})$ using $0.05 \mathrm{M}$ concentration.

\begin{tabular}{|c|c|c|c|c|c|c|c|c|c|c|c|}
\hline Grouping & Conv. (\%) & $\mathrm{N}$ & $\mathrm{T}\left({ }^{\circ} \mathrm{C}\right)$ & Grouping & Conv. (\%) & $\mathrm{N}$ & $\mathrm{C}(\mathrm{M})$ & Grouping & Conv. (\%) & $\mathrm{N}$ & $\mathrm{t}(\mathrm{min})$ \\
\hline A & 55.7074 & 27 & 50 & $\mathrm{~A}$ & 75.0630 & 27 & 0.05 & $\mathrm{~A}$ & 65.1000 & 27 & 8 \\
$\mathrm{~B}$ & 47.0852 & 27 & 35 & $\mathrm{~B}$ & 56.5778 & 27 & 0.1 & $\mathrm{~B}$ & 53.0926 & 27 & 5 \\
B & & & & & & & & & & \\
B & 46.2667 & 27 & 21 & $\mathrm{C}$ & 17.4185 & 27 & 0.5 & $\mathrm{C}$ & 30.8667 & 27 & 2 \\
\hline
\end{tabular}

Table 4: Duncan's test for the temperature, concentration and residence time (means with the same letter are not significantly different). 


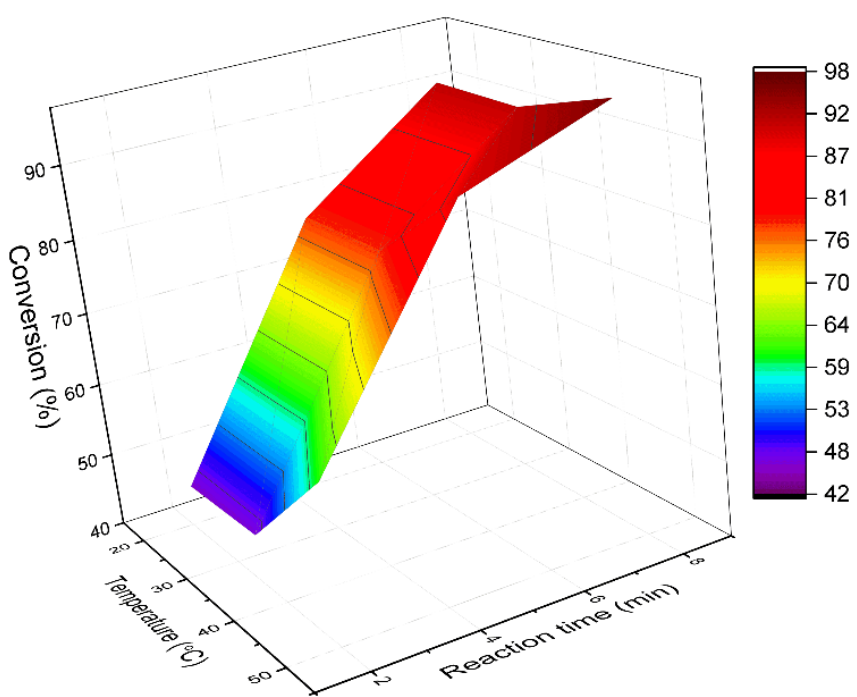

Figure 9: Effect on conversion of the interaction of residence time $(t)$ and Temperature $(T)$ using $0.05 \mathrm{M}$ concentration.

\section{Conclusions}

In this paper, a novel analytical approach in online sampling, separation and detection (QulProLi) successfully applied for the monitoring of a photo induced Claisen rearrangement reaction in microflow channels is described. A single analysis/sampling into a process-systemic approach is considered, considering also statistical approaches and needs posed by PAT for pharma quality control. As the FDA has decided to push the pharmaceutical companies to the transition from batch to flow, the establishment of a continuous-flow/PAT is urgently needed. The new sampling unit allowed the low volume and high speed sampling while maintaining very good repeatability and reproducibility of both the separation and detection of all reaction products. The developed analytical set-up avoids the complex sampling strategies of batch operation, as well as reduces drastically the manual work-up timing as well as the sampling volume. The increased sampling speed, allowed the screening of up to 27 process conditions in 24 hours; due to 3 times repetition, 81 samples were taken. In average, one sampling (at coupled continuous micro-flow reaction) took less than $7 \mathrm{~min}$. This fact becomes relevant compared to offline sampling especially in low flow rates. Testing reproducibility via comparing tests at 3 different days, all in all 243 samples were collected online, analysed and processed under almost automatized conditions. The results were enabled due to the speed of both online sampling and online UHPLC analysis. As the latter is established, it can be concluded that very fast online sampling opens the door for further intensification analysis for flow chemistry. Here the automatic online sampling was 40 $\%$ faster than offline sampling, keeping the same repeatability and robustness, and using more than 12 times less sample volume than used offline. Therefore, in the studied case, assuming a known systematic difference of $0.5 \% \pm 1.4$ compared to offline sampling and analysis, online analysis can be taken with the same reliability, avoiding the difficult to balance random errors. In addition, the photoClaisen reaction conditions in terms of conversion were monitored and successfully optimized at $50{ }^{\circ} \mathrm{C}$, $0.05 \mathrm{M}$ and $8 \mathrm{~min}$ with the results obtained in just three working days.

\section{Acknowledgements}

The authors acknowledge Ms. Bettina Schuhn, Mr. Thomas Ortmann and Dr. Thomas Glauner (Agilent Technologies) for supporting the modification of the UHPLC system for online sampling. This project was funded by the Horizon 2020: Marie Skolodowska-Curie Individual Fellowship awarded by Dr. Marc Escribà Gelonch under grant agreement number 659233. 


\section{References}

1. Plutschack MB, Pieber B, Gilmore K, Seeberger PH. Chem. Rev. 2017; 117:11796.

2. Mason BP, Price KE, Steinbacher JL, et al. Chem. Rev. 2007; 107:2300.

3. Ley SV, Fitzpatrick DE, Ingham RJ, Myers RM. Angew. Chem. Int. Ed. 2015; 54:3449.

4. Sans V, Cronin L. Chem. Soc. Rev. 2016; 45:2032.

5. Reizman BJ, Wang YM, Buchwald SL, Jensen KF. React. Chem. Eng. 2016; 1:658.

6. McMullen JP, Stone MT, Buchwald SL, Jensen KF. Angew. Chem. Int. Ed. Engl. 2010; 49:7076.

7. Sans V, Porwol L, Dragone V, Cronin L. Chem. Sci. 2015; 6:1258.

8. Pfeiffer SA, Nagl S. Methods Appl. Fluores. 2015; 3:34003.

9. Carlson, R.; Carlson, J.E. In Design and Optimization in Organic Synthesis; 2nd ed.; Elsevier: New York, 2005.

10. Minnich C; Hardy S; Kraemer S. Chem. Ing. Tech. 2016; 88:694.

11. Process or Product Monitoring and Control. In: NIST/SEMATECH e-handbook of statistical methods; NIST: 2012.

12. Hessel V, Vural-Gursel I, Wang Q, Noel T, Lang J. Chem. Eng. Technol. 2012; 35:1184.

13. Hessel V. Chem. Eng. Tech. 2009; 32:1655.

14. Hessel V, Kralisch D, Kockmann N, Noël T, Wang Q. ChemSusChem 2013; 6:746.

15. FDA. Pharmaceutical CGMPs for the 21st Century-a risk-based approach. Final Rep. Rockv. MD, 2004.

16. Escriba M, Hessel V, Rothstock S, et al. Green Chem. 2011; 13:1799.

17. Borukhova S, Noel T, Metten B, de Vos E, Hessel V. Green Chem. 2016; 18:4947.

18. Borukhova S, Noel T, Hessel V. ChemSusChem 2016; 9:67.

19. Database of ICH Guidelines, Compilation prepared by International Conference on Harmonisation of

Technical Requirements for Registration of Pharmaceuticals for Human Use (ICH),

http://www.ich.org/products/guidelines (last access 29-09-2017).

20. Database of FDA Guidance for Industry, Compilation prepared by Food and Drug Administration, https://www.fda.gov/RegulatoryInformation/Guidances/ucm081818.htm (last access 29-09-2017).

21. McMullen, JP.; Jensen, KF. An intelligent microreactor system for real-time optimization of a

chemical reaction. Proc. Int. Conf. Miniat. Syst. Chem. Life Sci. ( $\mu$ TAS), $12^{\text {th }}$; Chem. Biol. Microsyst. Soc.: San

Diego, 2008; pp. 1908.

22. Montgomery, D. C. In Design and analysis of experiments; John Wiley: New York, 2001.

23. Huyer W, Neumaier A. ACM Trans. Math. Soft. 2008; 35:1.

24. Tanaka R, Takahashi N, Nakamura Y, et al. Anal. Sci. 2017; 33:41.

25. Roggo Y, Chalus P, Maurer L, Martinez CL, et al. J. Pharm. Biomed. Anal. 2007; 44:683.

26. Ferstl W, Klahn T, Schweikert W, et al. Chem. Eng. Technol. 2007; 30:370.

27. Hausman DS, Cambron RT, Sakr A. Int. J. Pharm. 2005; 298:80.

28. Floyd TM, Schmidt MA, Jensen KF. Ind. Eng. Chem. Res. 2004; 44:2351.

29. Hu Y, Wang L, Huang X, Qian X, et al. IEEE T. Instrum. Meas. 2015; 64:1100.

30. Hübner S, Bentrup U, Budde U, et al. Org. Process Res. Dev. 2009; 13:952.

31. Araneda, J.F.; Boehringer, T.; Rehm, T.; Riegel, S. 254th ACS National Meeting \& Exposition, Washington, DC, Aug 20-24, 2017.

32. Maguire Y, Chuang IL, Zhang S, Gershenfeld, N. Proc. Natl. Acad. Sci. 2007; 104:9198.

33. Otsuka M, Koyama A, Hattori Y. RSC Adv. 2014; 4:17461.

34. Kamada K, Yoshimura S, Murata M, et al. Int. J. Pharm. 2009; 368:103.

35. Tanabe H, Otsuka K, Otsuka M. Anal. Sci. 2007; 23:857.

36. Otsuka M. Powder Technol. 2004; 141:244.

37. Koch MV, Marquardt B, Bonne U, et al. Selected Developments in Micro-analytical Technology. In Micro Instrumentation: for High Throughput Experimentation and Process Intensification - a Tool for PAT; Koch, M.V., Vandenbussche, K.M., Chrisman, R.W., Ed; Wiley-VCH Verlag GmbH \& Co. KGaA: Weinheim, Germany. DOI: 10.1002/9783527610624.ch9.

38. Marquardt B. Application of on-line raman spectroscopy to characterize and optimize a continuous microreactor. In Micro Instrumentation; Koch, M. V., Ed.; Wiley-VCH Verlag GmbH \& Co. KGaA: Weinheim, Germany, 2007.

39. Malherbe CJ, de Beer D, Joubert E. Int. J. Mol. Sci. 2012; 13:3101.

40. McMullen JP, Jensen KF. Annu. Rev. Anal. Chem. 2010; 3:19.

41. Albrecht JW, El-Ali J, Jensen KF. Anal. Chem. 2007; 79:9364. 
42. Fernandez-Suarez M, Wong SYF, Warrington BH. Lab. Chip 2002; 2:170.

43. Garcia-Egido E, Spikmans V, Wong SYF, Warrington BH. Lab. Chip 2003; 3:73.

44. Schwalbe T, Kadzimirsz D, Jas G. QSAR Comb. Sci. 2005; 24:758.

45. Griffiths-Jones CM, Hopkin MD, Jonsson D, Ley SV, et al. J. Comb. Chem. 2007; 9:422.

46. Koch K, van Weerdenburg BJA, Verkade JMM, Nieuwland PJ, Rutjes FPJT, van Hest JCM. Org. Process Res. Dev. 2009; 13:1003.

47. Shih CY, Chen Y, Xie J, et al. J. Chromatogr. A 2006; 1111:272.

48. McMullen JP, Jensen KF. Org. Process Res. Dev. 2010; 14:1169.

49. Haven JJ, Zaquen N, Rubens M, Junkers T. Macromol. React. Eng. 2017; 11:1700016.

50. Murphy ER, Martinelli JR, Zaborenko N, Buchwald SL, Jensen KF. Angew. Chem. Int. Ed. 2007; 46:1734.

51. Ratner DM, Murphy ER, Jhunjhunwala M., et al. Chem. Commun. 2005; 5:578.

52. Tadepalli S, Halder R, Lawal A. Chem. Eng. Sci. 2007; 62:2663.

53. a) Floyd TM, Schmidt MA, Jensen KF. Ind. Eng. Chem. Res. 2004; 44:2351.

b) Quiram DJ, Jensen KF, Schmidtt MA, et al. Ind. Eng. Chem. Res. 2007; 46:8319.

54. El-Ali J, Sorger PK, Jensen KF. Nature 2006; 442:403.

55. Gerber D, MaerkI SJ, Quake SR. Nat. Methods 2009; 6:71.

56. Srisa-Art M, Kang DK, Hong J, Park H, et al. ChemBioChem 2009; 10:1605.

57. Ajmera SK, Delattre C, Schmidt MA, Jensen KF. J. Catal. 2002; 209:401.

58. Floyd TM, Schmidt MA, Jensen KF. Ind. Eng. Chem. Res. 2004; 44:2351.

59. Fang H, Xiao Q, Wu F, et al. J. Org. Chem. 2010; 75:5619.

60. Attiya S, Jemere AB, Tang T, Fitzpatrick $G$, et al. Electrophoresis 2001; 22:318.

61. Lin YH, Lee GB, Li CW, Huang GR, Chen SH. J. Chromatogr. A 2001; 937:115.

62. Schlund M, Gilbert SE, Schnydrig S, Renaud P. Sensor. Actuat. B-Chem. 2007; 123:1133.

63. Koch K, van Weerdenburg BJA, Verkade JMM, Nieuwland PJ, et al. Org. Process Res. Dev. 2009; 13:1003.

64. Yu L. Pharm. Res. 2008; 25:781.

65. Shahbazali E, Spapens M, Kobayashi H, et al. Chem. Eng. J. 2015; 281:144.

66. Shahbazali E, Noël T, Hessel V. J. Flow Chem. 2016; 6:252.

67. Pitchumani K, Warrier M, Ramamurthy V. J. Am. Chem. Soc. 1996; 118:9428.

68. n-Butanol. BASF petrochemicals (M 2084 e) edition July 2014.

http://www.solvents.basf.com/portal/streamer?fid=278912 (last access October 2017).

69. Pearson K. Philos. Mag. Series 5. 1900; 50:157.

70. SAS institute. Base SAS 9.2 Procedures Guide, Statistical Procedures; 2nd Ed; SAS Institute, Cary, NC, 2009.

71. Duncan D B. Biometrics. 1955; 11: 1. 